Document downloaded from:

http://hdl.handle.net/10251/122234

This paper must be cited as:

Guijarro-Real, C.; Rodríguez Burruezo, A.; Prohens Tomás, J.; Fita, A. (2018). Importance of the growing system in the leaf morphology of Diplotaxis erucoides. Acta Horticulturae. 1202:25-32. https://doi.org/10.17660/ActaHortic.2018.1202.4

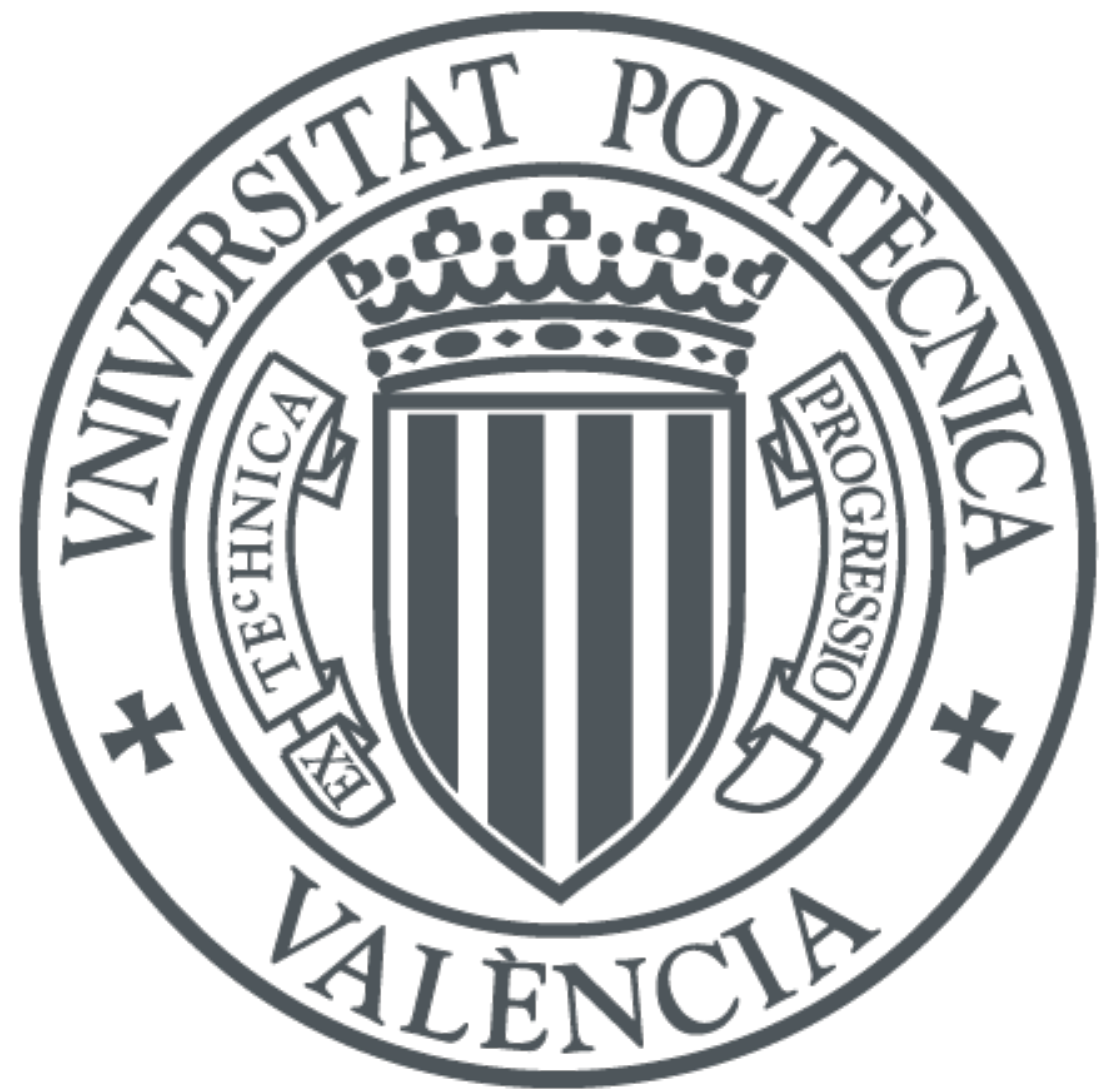

The final publication is available at

http://doi.org/10.17660/ActaHortic.2018.1202.4

Copyright International Society for Horticultural Science (ISHS)

Additional Information 


\title{
Importance of the growing system in the leaf morphology of Diplotaxis erucoides
}

\author{
C. Guijarro-Real, A. Rodríguez-Burruezo, J. Prohens and A. Fita \\ Instituto de Conservación y Mejora de la Agrodiversidad Valenciana (COMAV), Universitat Politècnica de \\ València, Valencia, Spain.
}

\begin{abstract}
Worldwide there are around 7,000 edible plant species which are known to have been consumed by humans. Wall rocket (Diplotaxis erucoides) is an herbaceous plant widespread in the Mediterranean region. As a leafy vegetable, this plant can be used as a component of salads, providing a characteristic, mild pungent flavour. Due to the potential interest of this species, we are initiating a breeding program, of which the establishment of a correct growing system is an important part. In this study, two wild, pre-selected populations of wall rocket were analysed and compared with a commercial variety. Material was grown in the late autumn-winter season under two different systems, greenhouse and field, and leaf morphological traits were evaluated. Remarkable differences were found among the growing systems in the morphology of the leaves as well as in the leaf colour. Plants growing in greenhouse had larger total leaf area than those growing in the field. The leaf length/width ratio was greater in greenhouse than in the field for the wild populations, while it did not change significantly in the commercial variety. Leaf lobation was more marked in the field in all populations assayed. The relative chlorophyll content decreased in the greenhouse system, while both the hue angle and chroma increased compared to the field system. Despite the larger size of the leaves in greenhouse, their lighter colour and few lobation makes them less attractive for the salads market. Therefore, cultivating this species in field seems to offer a better potential for a ready-to-eat product.
\end{abstract}

Keywords: leaf color, leafy vegetable, morphological traits, wall rocket

\section{INTRODUCTION}

More than 7,000 species of plants have been used in the past for human or animal feeding (Food and Agricultural Organization, 2015), most of them gathered from wild. However, there are only around 200 crops established in different cultures.

New trends have appeared in markets in the last decades. Consumers are demanding foods with new flavours and textures, as well as rich in bioactive compounds. This is probably the reason why markets started focusing their attention on the traditional cuisine of Mediterranean cultures, with a vast tradition in collecting wild edible plants for food. It is evidenced by the large number of studies about wild plants traditionally used, the way to consume them and their nutritional quality (e.g. Pieroni et al., 2005; Guarrera and Savo, 2013; Morales et al., 2014). A good example of minor leafy crop that has increased in popularity is rocket, which is today widely consumed as baby leaf (Cavaiuolo and Ferrante, 2014). The name of this crop encompasses two species from the family Brassicaceae, Eruca 
sativa (salad rocket) and Diplotaxis tenuifolia (wild rocket), being the second one the most popular in Europe (Cavaiuolo and Ferrante, 2014). However, apart from salad and wild rocket, other species from these genera have been used in the traditional Mediterranean cuisine and may be interesting crops. We have focussed this study on the particular case of wall rocket. Wall rocket (Diplotaxis erucoides) is an annual plant recognised for the shape of their leaves and the racemes of white flowers. Widespread in the Mediterranean region, including Europe, North Africa and Near East to Iraq (Martínez-Laborde, 1997), it is considered weed for many crops. As other wild plants, it has been traditionally consumed in different Mediterranean countries such as Spain or Italy (Tardío et al., 2006; Lentini and Venza, 2007). Leaves are the organs generally consumed, raw in salads or cooked (Lentini and Venza, 2007), providing special, little pungent flavour clearly different to the rocket flavour. It has been also reported the use of the flowers to decorate some dishes (Bianco et al., 1998).

Not considered so far as potential crop, few studies with this species have been done. It is possible to find references in bibliography regarding their nutritional values and even sensory attributes but mainly as control for other rockets (Bennett et al., 2006; D'Antuono et al., 2008; D'Antuono et al., 2009). However, there is a lack of morphological and agronomical studies which may help to develop new cultivated types.

Thus, culture conditions should be studied in order to identify the optimal ones for a commercial production. This is a key point for minimal processed vegetables, since it is known that culture conditions including growing system, climatic conditions or soil conditions, can affect the quality of the final product (Nicola et al., 2009). The aim of this preliminary study, which is part of a breeding program that is been developed, is to assess in what degree relevant morphological traits of wall rocket are modified depending on the growing system.

\section{MATERIALS AND METHODS}

\section{Plant material and cultivation conditions}

Two pre-selected accessions and the cv. Wasabi (Shamrock Seed CO., USA) were used. Accessions DER055-1 and DER081-1 were regenerated from wild populations from the

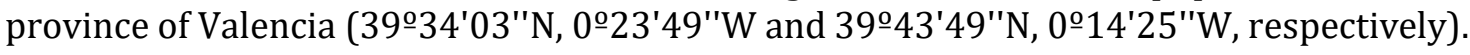

The study was simultaneously conducted in a heated glass greenhouse and an unheated field protected with a mesh against pests, at the Universitat Politècnica de València (Valencia, Spain), during the late autumn-winter season. Seeds were first treated with sodium hypochlorite $2.5 \%$ and gibberellic acid $100 \mathrm{ppm}$ in order to break dormancy.

Treated seeds were grown in peat media for two days at $25^{\circ} \mathrm{C}$ and long-day conditions $(16 \mathrm{~h} / 8 \mathrm{~h})$, then moved to greenhouse. Plants destined to greenhouse were directly sown in $6.2 \mathrm{~L}$ pots. On the contrary, plants destined to the field were grown in seedling trays for two weeks and then transplanted. Four biological replicates were prepared and the $4^{\text {th }}$ leaf of five plants per replicate were analysed. All plants were harvested at the emergence of the first flower buds. 


\section{Morphological traits}

Traits were selected on the basis of descriptors for rocket Eruca spp. (IPGRI, 1999) and adapted to the species of study. Chlorophyll content and colour were also considered.

Traits related to leaf shape were visually measured and leaves classified according to their leaf blade shape (elliptic, obovate, spatulate), margin shape (crenate, crenate-dentate, dentate) and number and intensity of lobation (in a 0-5 scale where 0 means absent and 5 very deep lobes). The relative chlorophyll content was measured using a chlorophyll meter (SPAD-502 Plus, Konica Minolta Inc., Japan) and the L, a, b colour parameters with a colorimeter (CR-400, Konika Minolta Inc., Japan). In order to analyse length, width, area and perimeter, leaves were scanned and processed using Tomato Analyzer 3.0 software (Brewer et al., 2006). This tool was also used for a second measurement of the colour parameters ( $\mathrm{L}^{*}$, $\left.a^{*}, b^{*}\right)$ and to calculate the hue angle $\left(H=\arctan \left(b^{*} / a^{*}\right)\right)$ and chroma $\left(C=\left[\left(a^{*}\right)^{2}+\left(b^{*}\right)^{2}\right]^{1 / 2}\right)$.

\section{Data analysis}

Quantitative data were processed using a multifactorial analysis of variance (ANOVA) and least significant difference (LSD) values were calculated with a level of significance of $5 \%$. Interactions among populations and growing systems were also studied. Qualitative attributes were studied using the cross-tabulation procedure.

\section{RESULTS}

\section{Traits related to leaf shape and size}

Data from quantitative attributes are shown in Table 1. Higher values for length and leaf area were obtained in greenhouse. Wasabi developed the smallest leaves within systems. DER055-1 had the highest perimeter within each system and also presented the widest leaves in the field while this difference was not detected in the greenhouse.

The length/width ratio gives an approximation of the shape (Egea-Gilabert et al., 2013). Thus, growing plants in greenhouse led to narrower leaves. In this system, Wasabi showed broader leaves than DER051-1 and DER081-1. However, an interaction among accessions and growing systems was described for this trait, so in the field DER055-1 was more similar to Wasabi, while DER081-1 showed the narrowest leaves.

In Fig. 1 the percentage of leaves with a specific blade shape has been represented, for each accession and system evaluated. In general, the dominant shape described in the field was spatulate (85\%, 70\% and 80\% for DER055-1, DER081-1 and Wasabi, respectively), in combination with obovate leaves for DER081-1 and Wasabi and eliptic for DER055-1. In greenhouse, wild accessions presented $50 \%$ of leaves with spatulate shape, while total of leaves in Wasabi were classified as obovate, shape that was also more remarkable in DER081-1 than in DER055-1. DER055-1 presented the highest percentage of elliptic leaves in both systems.

The intermediate crenate-dentate shape was dominant in DER081-1 and Wasabi. In DER055-1 the percentage was less than 50\%. This accession had the highest percentage of 
dentate margin. The crenate shape was low in general with the exception of DER081-1 cultivated in the field, rising up to $35 \%$.
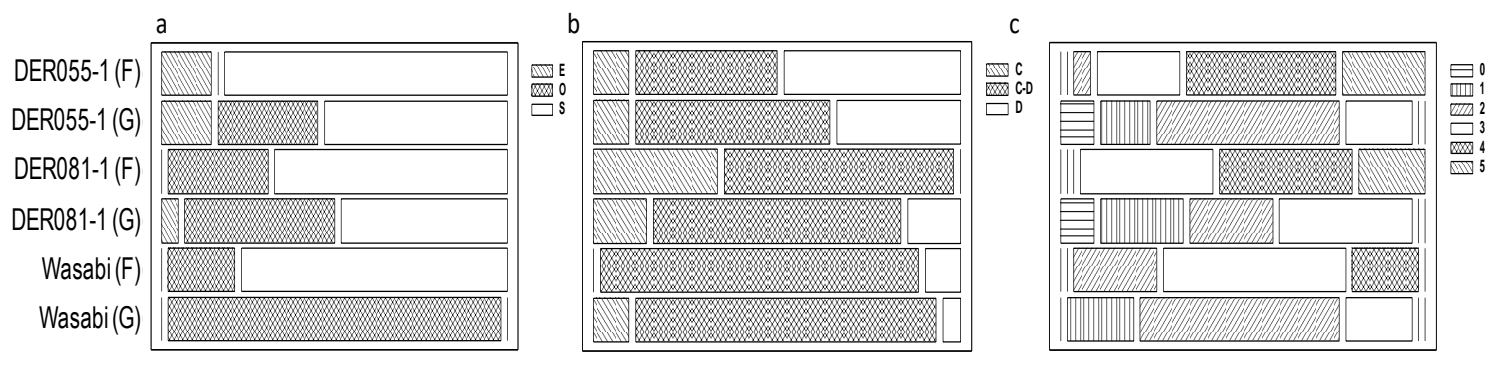

Fig.1. Graphical representation of the percentage of samples classified according to a) leaf blade shape (E: elliptic, O: obovate, S: spatulate), b) leaf margin (C: crenate, C-D: crenate-dentate, D: dentate) and c) intensity of lobation (scale $0-5$ where 0 means absent and 5 very deep lobation).

Lobation was clearly distinct between systems (Table 1 and Fig. 1, respectively). While plants in the field presented higher degree in terms of number and depth of the interlobe space, blades were more entire in greenhouse. Wasabi was the most homogeneus between systems with dominance of intermediate lobation (2-3 in the scale used). Both DER055-1 and DER081-1 developed relative high intensity in the field. However, in greenhouse DER055-1 looked similar to Wasabi, while DER081-1 presented higher intensity.

\section{Traits related to leaf colour}

As indicated in Material and Methods, colour was physically measured with a colorimeter and also calculated from the scanned image. Correlations were above to $0.9(\mathrm{P}=$ 0.05) (data not shown) so software data were validated and used for calculating hue angle and chroma.

Mean values are shown in Table 2. There were significant differences between systems and interactions with accessions for most attributes. Plants in greenhouse showed higher luminosity, hue angle and chroma, corresponding with higher absolute values of a* and $b^{*}$ in comparison with the field. There were significant differences among accessions only for $L^{*}$ in greenhouse and for hue in both systems. DER081-1 in greenhouse was the lightest accession and presented the lowest hue angle. The relative content in chlorophyll was higher in the field, where no differences were found among accessions. In greenhouse, DER055-1 highlighted for its content, being in any case lower than values from the field.

A remarkable correlation was established between colour and chlorophyll content $(\mathrm{P}=0.05)$, specifically for luminosity $(-0.856)$ and chroma $(-0.887)$.

\section{DISCUSSION}

In this study we measured some relevant traits for the consumer (Colonna et al., 2016) In the case of ready-to-eat products, colour is one of the most important traits to consider (Nicola et al., 2009; Egea-Gilabert et al., 2013). Our results showed that the main 
Table 1. Mean values and individual errors of the quantitative shape and size traits measured for each accession (A) in the two growing systems (GS), greenhouse (G) and field $(F)$. Different letters among the three accessions for each trait and growing system indicate significant differences (LSD, $P<0.05)$ and ${ }^{*}$, ns means significant at $\mathrm{P}=0.05$ and non-significant, respectively.

\begin{tabular}{|c|c|c|c|c|c|c|c|c|c|c|c|c|}
\hline \multirow[t]{2}{*}{ Accession } & \multicolumn{2}{|c|}{ Length (cm) } & \multicolumn{2}{|c|}{ Widht (cm) } & \multicolumn{2}{|c|}{ Length/Width ratio } & \multicolumn{2}{|c|}{ Perimeter (cm) } & \multicolumn{2}{|c|}{ Area $\left(\mathrm{cm}^{2}\right)$} & \multicolumn{2}{|c|}{ Number of lobes } \\
\hline & G & $\mathrm{F}$ & G & $\mathbf{F}$ & G & $\mathbf{F}$ & G & $\mathbf{F}$ & G & $\mathbf{F}$ & G & $\mathbf{F}$ \\
\hline DER055-1 & $9.4 \pm 0.4 b$ & $7.6 \pm 0.3 a b$ & $2.9 \pm 0.1 \mathrm{a}$ & $3.0 \pm 0.1 \mathrm{~b}$ & $3.3 \pm 0.1 b$ & $2.6 \pm 0.1 \mathrm{a}$ & $26.0 \pm 1.1 \mathrm{~b}$ & $28.3 \pm 1.9 b$ & $12.3 \pm 0.9 a$ & $10.7 \pm 9.9 a$ & $5 \pm 0 a$ & $8 \pm 0 a$ \\
\hline DER081-1 & $9.1 \pm 0.3 b$ & $8.0 \pm 0.3 b$ & $2.7 \pm 0.1 \mathrm{a}$ & $2.6 \pm 0.1 \mathrm{a}$ & $3.4 \pm 0.1 b$ & $3.1 \pm 0.1 b$ & $\begin{array}{c}24.9 \pm 1.0 \mathrm{a} \\
\mathrm{b}\end{array}$ & $\begin{array}{c}25.4 \pm 0.9 a \\
b\end{array}$ & $11.1 \pm 0.7 a$ & $9.9 \pm 0.6 a$ & $6 \pm 1 a$ & $8 \pm 0 \mathrm{a}$ \\
\hline cv. Wasabi & $8.0 \pm 0.4 a$ & $7.0 \pm 0.2 \mathrm{a}$ & $2.9 \pm 0.1 \mathrm{a}$ & $2.6 \pm 0.1 \mathrm{a}$ & $2.8 \pm 0.1 \mathrm{a}$ & $2.6 \pm 0.0 \mathrm{a}$ & $22.3 \pm 1.1 a$ & $22.9 \pm 0.7 a$ & $11.1 \pm 0.9 a$ & $9.0 \pm 0.4 a$ & $6 \pm 0 \mathrm{a}$ & $8 \pm 0 \mathrm{a}$ \\
\hline Average & $8.8 \pm 0.3^{*}$ & $7.5 \pm 0.3$ & $2.8 \pm 0.1$ & $2.8 \pm 0.1$ & $3.2 \pm 0.1^{*}$ & $2.7 \pm 0.1$ & $24.4 \pm 1.1$ & $25.5 \pm 1.3$ & $11.5 \pm 1.2^{*}$ & $9.9 \pm 0.6$ & $5 \pm 0$ & $8 \pm 0^{*}$ \\
\hline$A \times G S$ & \multicolumn{2}{|c|}{ ns } & \multicolumn{2}{|c|}{ ns } & & \multicolumn{2}{|c|}{ ns } & \multicolumn{2}{|c|}{ ns } & \multicolumn{2}{|c|}{ ns } \\
\hline
\end{tabular}

Table 2. Mean values and individual errors of the colour traits in the three accessions (A) and growing systems (GS), greenhouse (G) and field (F). Different letters among the three accessions for each trait and growing system indicate significant differences (LSD, $P<0.05)$ and *, ns means significant at $P=0.05$ and non-significant, respectively.

\begin{tabular}{|c|c|c|c|c|c|c|c|c|}
\hline \multirow[t]{2}{*}{ Accessions } & \multicolumn{2}{|c|}{$L^{*}$} & \multicolumn{2}{|c|}{ Hue angle } & \multicolumn{2}{|c|}{ Chroma } & \multicolumn{2}{|c|}{ Chlorophyll content (SPAD) } \\
\hline & $\mathbf{G}$ & $F$ & $\mathbf{G}$ & $\mathbf{F}$ & $\mathbf{G}$ & $\mathbf{F}$ & G & $F$ \\
\hline DER055-1 & $46.9 \pm 0.4 a$ & $43.4 \pm 0.5 a$ & $129.1 \pm 0.2 b$ & $128.0 \pm 0.3 a b$ & $35.9 \pm 0.8 a$ & $29.8 \pm 0.5 a$ & $36.1 \pm 0.9 b$ & $43.3 \pm 1.0 \mathrm{a}$ \\
\hline DER081-1 & $49.3 \pm 0.4 b$ & $43.2 \pm 0.5 \mathrm{a}$ & $127.8 \pm 0.3 a$ & $127.2 \pm 0.4 a$ & $37.7 \pm 0.6 a$ & $28.4 \pm 0.7 a$ & $32.1 \pm 0.5 a$ & $45.4 \pm 0.5 \mathrm{a}$ \\
\hline cv. Wasabi & $46.5 \pm 0.3 a$ & $42.5 \pm 0.3 a$ & $128.6 \pm 0.1 b$ & $128.8 \pm 0.3 b$ & $37.1 \pm 0.5 a$ & $30.0 \pm 0.6 a$ & $33.8 \pm 0.6 a$ & $44.7 \pm 1.0 \mathrm{a}$ \\
\hline $\begin{array}{l}\text { Average } \\
A X G S\end{array}$ & $47.6 \pm 0.4^{*}$ & $43.4 \pm 0.4$ & $128.5 \pm 0.2^{*}$ & $128.0 \pm 0.3$ & $36.9 \pm 0.6^{*}$ & $29.4 \pm 0.6$ & $34.0 \pm 0.7$ & $44.5 \pm 0.9^{*}$ \\
\hline
\end{tabular}


differences in colour were between systems but any of the three accessions clearly highlighted. Accessions growing in the field presented darker green leaves, with lower values of chroma, hue angle and $\mathrm{L}^{*}$ but higher for the chlorophyll content. This leads us to think that field cultivation is more suitable for growing wall rocket, as other authors suggested dark colours for salad leafy vegetables as more accepted by the market (EgeaGilabert et al. 2014). The explanation may be that consumers associate dark-green leaves with "freshness" so they are more attractive than the lighter ones, which look "senescent" and "old" (Koukounaras et al 2007). Nevertheless, in this assay plants growing in the field conditions showed as well signs of anthocyanin accumulation (difficult to be reflected in the colour results), probably due to cold stress (Jin et al., 2009). Those spots may be undesirable for marketing so probably the harsh winter should be avoid.

The shape seems to be another attribute to be considered. In their work with salad rocket, Bell et al. (2017) revealed that consumers generally preferred the more lobed shape rather than the broader blade. These authors hypothesized that this preference was due to its similarity with the "common rocket shape". Thus, developing a lobed cultivar may probably help the new crop to be introduced in markets. Since the number and intensity of lobation was superior in the field, the commercial crop in this system seems to be a good option. On the other hand, we have not found references where preferences in leaf and margin shape were studied. Nevertheless, we consider that the dentate margin looks more "aggressive" than the crenate or intermediate shape, so in this sense the accession DER0811 may be better option for being included in a breeding program rather than DER055-1.

The third group of traits included those related to leaf size. Leaves were longer in greenhouse, but no differences were found in width between systems. Consequently, greater length positive conditioned greater total area and narrower shape. Differences between systems could be explained by the coexistence of high temperatures and humidity in greenhouse combined with higher intensity of light in comparison with the field. Cookson et al. (2005) observed that subjecting plants of Arabidopsis thaliana to shade conditions caused a significant reduction in leaf area. On the other hand, considering the three accessions evaluated, we found a remarkable difference between Wasabi and the wild accessions. While the first one was smaller and broader, the wild ones were longer and narrower. Thus, the wild accessions could be used for developing a new, size-different cultivar.

\section{CONCLUSION}

The results suggest that growing this crop in the field would be a better option rather than the culture in greenhouse, at least for Mediterranean regions similar in conditions to Valencia, since plants in this system presented more desirable colour and shape. However, non-controlled conditions may have the disadvantage of inducing undesirable traits if plants grow under stress, especially cold and intense rains, affecting to the final product.

Finally, differences found among accessions suggest that DER081-1 may be included in a breeding program in order to obtain a commercial cultivar, different in shape and size to Wasabi, whereas the accession DER055-1 is not probably desirable for the program. But results of the agronomical assays that we are developing have to be combined with nutritional information, especially considering the possible presence of non-nutritional compounds such as nitrates, very common in leafy vegetables. 


\title{
AKNOWLEDGEMENTS
}

\author{
C. Guijarro-Real thanks the Ministerio de Educación, Cultura y Deporte of Spain \\ (MECD) for a predoctoral grant (BOE-A-2014-13539).
}

\section{Literature cited}

Bell, L., Methven, L., and Wagstaff, C. (2017). The influence of phytochemical composition and resulting sensory attributes on preference for salad rocket (Eruca sativa) accessions by consumers of varying TAS2R38 diplotype. Food Chem. 222, 6-17

Bennett, R.N., Rosa, E.A.S., Mellon, F.A., and Kroon, P.A. (2006). Ontogenic profiling of glucosinolates, flavonoids, and other secondary metabolites in Eruca sativa (salad rocket), Diplotaxis erucoides (wall rocket), Diplotaxis tenuifolia (wild rocket), and Bunias orientales (turkish rocket). J. Agr. Food Chem. 54, 4005-4015

Bianco, V.V., Santamaria, P., and Elia, A. (1998). Nutritional value and nitrate content in edible wild species used in Southern Italy. Acta Hortic. 467, 71-90

Brewer, M.T., Lang, L., Fujimura, K., Dujmovic, N., Gray, S., and van der Knaap, E. (2006). Development of a controlled vocabulary and software application to analyze fruit shape variation in tomato and other plant species. Plant Physiol. 141, 15-25

Cavaiuolo. M., and Ferrante, A. (2014). Nitrates and glucosinolates as strong determinants of the nutritional quality in rocket leafy salads. Nutrients $6,1519-1538$

Colonna, E., Rouphael, Y., Barbieri, G., de Pascale, S. (2016). Nutritional quality of ten leafy vegetables harvested at two light intensities. Food Chem. 199, 702-710

Cookson, S.J., Van Lijsebettens, M., and Granier, C. (2005). Correlation between leaf growth variables suggest intrinsic and early controls of leaf size in Arabidopsis thaliana. Plant Cell Environ. 28, 1355-1366

D'Antuono, L.F., Elementi, S., and Neri, R. (2008). Glucosinolates in Diplotaxis and Eruca leaves: Diversity, taxonomic relations and applied aspects. Phytochemistry 69, 187-199

D'Antuono, L.F., Elementi, S., Neri, R. (2009). Exploring new potential health-promoting vegetables: glucosinolates and sensory attributes of rocket and related Diplotaxis and Eruca species. J. Sci. Food Agric. 89, 713-722

Egea-Gilabert, C., Niñirola, D., Conesa, E., Candela, M.E., Fernández, J.A. (2013). Agronomical use as baby leaf salad of Silene vulgaris based on morphological, biochemical and molecular traits. Sci. Hortic. 152, 35-43

Egea-Gilabert, C., Ruiz-Hernández, V., Parra, M.A., Fernández, J.A. (2014). Characterization of purslane (Portulaca oleracea L.) accessions: Suitability as ready-to-eat product. Scientia Horticulturae 172, 73-81

Food and Agricultural Organization. (2015). www.fao.org

Guarrera, P.M., and Savo, V. (2013). Perceived health properties of wild and cultivated food plants in local and popular traditions of Italy: A review. J. Ethnopharmacol. 146, 659-680

IPGRI. (1999). Descriptors for rocket (Erucca spp.). International Plant Genetic Resources Institute, Rome, Italy. pp.56

Jin, J., Koroleva, O.A., Gibson, T., Swanston, J., Magan, J., Zhang, Y., Rowland, I.R., and Wagstaff, C. (2009). Analysis of phytochemical composition and chemoprotective capacity of rocket (Eruca sativa and Diplotaxis tenuifolia) leafy salad following cultivation in different environments. J. Agr. Food Chem. 57, 5227-5234 
Koukounaras, A., Siomos, A.S., and Sfakiotakis, E. (2007). Postharvest $\mathrm{CO}_{2}$ and ethylene production and quality of rocket (Eruca sativa Mill.) leaves as affected by leaf age and storage temperature. Postharvest Biol. Tec. 46, 167173.

Lentini, F., and Venza. F. (2007). Wild food plants of popular use in Sicily. J. Ethnobiol. Ethnomed. 3, 15

Martínez-Laborde, J.B. (1997). A brief account of the genus Diplotaxis. In Rocket: a Mediterranean crop for the world, S. Padulosi, and D. Pignone, eds. (Rome, Italy: International Plant Genetic Resources Institute), p.13-22.

Morales, P., Ferreira, I., Carvalho, AM., Sánchez-Mata, M.C., Cámara, M., Fernández-Ruiz, V., Pardo-de-Santayana, M., and Tardío, J. (2014). Mediterranean non-cultivated vegetables as dietary sources of compounds with antioxidant and biological activity. LWT Food Sci. Technol. 55, 389-396

Nicola, S., Tibaldi, G., and Fontana, E. (2009). Fresh-cut produce quality: implications for a systems approach. In: Postharvest Handling. A system approach, $2^{\text {nd }}$ edn, W.J. Florkowski, R.L. Shewfelt, B. Brueckner, and S.E. Prussia, eds. (Burlington, MA, USA: Academic Press), p.247-282

Pieroni, A., Nebel, S., Santoro, R.F., and Heinrich. M. (2005). Food for two seasons: Culinary uses of non-cultivated local vegetables and mushrooms in a south Italian village. Int. J. Food Sci. Nutr. 56, 245-272

Tardío, J., Pardo-de-Santayana, M., and Morales, R. (2006) Ethnobotanical review of wild edible plants in Spain. Bot. J. Linn. Soc. 152, 27-71

The original publication is available at Acta Hortic. 1202, 25-32. DOI: 10.17660/ActaHortic.2018.1202.4 